\title{
The Single Graduate Medical Education (GME) Accreditation System Will Change the Future of the Family Medicine Workforce
}

\author{
Michael R. Peabody, PhD, Thomas R. O'Neill, PhD, Aimee R. Eden, PhD, \\ and James C. Puffer, MD
}

Background: Due to the Accreditation Council for Graduate Medical Education (ACGME)/American Osteopathic Association (AOA) single-accreditation model, the specialty of family medicine may see as many as 150 programs and 500 trainees in AOA-accredited programs seek ACGME accreditation. This analysis serves to better understand the composition of physicians completing family medicine residency training and their subsequent certification by the American Board of Family Medicine.

Methods: We identified residents who completed an ACGME-accredited or dual-accredited family medicine residency program between 2006 and 2016 and cross-tabulated the data by graduation year and by educational background (US Medical Graduate-MD [USMG-MD], USMG-DO, or International Medical Graduate-MD [IMG-MD]) to examine the cohort composition trend over time.

Results: The number and proportion of osteopaths completing family medicine residency training continues to rise concurrent with a decline in the number and proportion of IMGs. Take Rates for USMG-MDs and USMG-IMGs seem stable; however, the Take Rate for the USMG-DOs has generally been rising since 2011.

Conclusions: There is a clear change in the composition of graduating trainees entering the family medicine workforce. As the transition to a single accreditation system for graduate medical education progresses, further shifts in the composition of this workforce should be expected. (J Am Board Fam Med 2017;30:838-842.)

Keywords: Accreditation, Graduate Medical Education, Osteopathic Medicine, Workforce

In 2014, the Accreditation Council for Graduate Medical Education (ACGME), American Osteopathic Association (AOA), and American Association of Colleges of Osteopathic Medicine reached a historic agreement on the creation of a single accreditation system for graduate medical education. ${ }^{1}$ When fully implemented in July 2020, all graduate medical education in the United States will be accredited by a single ac-

This article was externally peer reviewed.

Submitted 8 February 2017; revised 17 May 2017; accepted 17 May 2017.

From the American Board of Family Medicine, Lexington, KY.

Funding: none.

Conflict of interest: MRP, TRO, ARE, and JCP are employees of the American Board of Family Medicine.

Corresponding author: Michael R. Peabody, PhD, 1648 McGrathiana Pkwy, Ste 550, Lexington, KY 40511 (E-mail: mpeabody@theabfm.org). crediting agency, the ACGME, and this will guarantee that training of osteopathic and allopathic physicians in every specialty will be guided by a single set of standards.

Based on current graduation rates (http://www. osteopathic.org/inside-aoa/about/aoa-annualstatistics/Pages/osteopathic-medical-schools.aspx; accessed February 6, 2017), over 5000 graduates of 33 osteopathic medical schools will enter ACGMEaccredited training in July 2020, and this number will likely increase as 12 new osteopathic medical schools currently seeking accreditation by the AOA Commission on Osteopathic College Accreditation are approved. The impact on the specialty of Family Medicine will be significant. Although close to 100 osteopathic family medicine residency programs are dually accredited (currently accredited by both the ACGME and the AOA), as many as an additional 150 programs solely accredited by the 
Table 1. Percentage of Allopathic and Osteopathic Physicians Completing Family Medicine Residency Programs

\begin{tabular}{|c|c|c|c|c|c|c|c|c|}
\hline \multirow{2}{*}{$\begin{array}{l}\text { Year of Residency } \\
\text { Completion }\end{array}$} & \multicolumn{2}{|c|}{ USMG-DO } & \multicolumn{2}{|c|}{ IMG-MD } & \multicolumn{2}{|c|}{ USMG-MD } & \multicolumn{2}{|c|}{ Total } \\
\hline & $\mathrm{N}$ & $\%$ & $\mathrm{~N}$ & $\%$ & $\mathrm{~N}$ & $\%$ & $\mathrm{~N}$ & $\%$ \\
\hline 2006 & 444 & 14.0 & 1177 & 37.1 & 1549 & 48.9 & 3170 & 100 \\
\hline 2007 & 491 & 15.6 & 1153 & 36.6 & 1505 & 47.8 & 3149 & 100 \\
\hline 2008 & 459 & 14.7 & 1234 & 39.5 & 1428 & 45.8 & 3121 & 100 \\
\hline 2009 & 441 & 13.9 & 1296 & 40.8 & 1443 & 45.4 & 3180 & 100 \\
\hline 2010 & 485 & 15.5 & 1253 & 40.1 & 1386 & 44.4 & 3124 & 100 \\
\hline 2011 & 525 & 16.3 & 1268 & 39.3 & 1431 & 44.4 & 3224 & 100 \\
\hline 2012 & 563 & 17.3 & 1282 & 39.4 & 1408 & 43.3 & 3253 & 100 \\
\hline 2013 & 557 & 17.3 & 1204 & 37.4 & 1457 & 45.3 & 3218 & 100 \\
\hline 2014 & 612 & 18.1 & 1190 & 35.1 & 1586 & 46.8 & 3388 & 100 \\
\hline 2015 & 681 & 20.0 & 1162 & 34.1 & 1564 & 45.9 & 3407 & 100 \\
\hline 2016 & 718 & 20.7 & 1172 & 33.7 & 1583 & 45.6 & 3473 & 100 \\
\hline Total & 5976 & 16.7 & 13,391 & 37.5 & 16,340 & 45.8 & 35,707 & 100 \\
\hline
\end{tabular}

USMG-DO, US Medical Graduate-DO; USMG-MD, US Medical Graduate-MD; IMG-MD, International Medical Graduate-MD.

AOA may seek ACGME accreditation with the potential to add another 500 family medicine trainees per year (http://www.osteopathic.org/insideaoa/Education/students/match-program/Pages/ match-results.aspx; accessed February 6, 2017). Given the transition to the single accreditation model and these dynamics, we wished to better understand the composition of physicians completing family medicine residency training and their subsequent certification by the American Board of Family Medicine (ABFM).

\section{Methods \\ Data}

We used the ABFM's Resident Training Management System (RTMS) to identify residents who completed an ACGME-accredited family medicine residency program between 2006 and 2016. ACGMEaccredited residencies accept both allopathically and osteopathically trained physicians into their programs and because RTMS is used by all ACGME-accredited programs, it necessarily includes dually accredited (ACGME and AOA) programs. The roster of residents was extracted from RTMS along with 1) the year they graduated from residency, 2) an indicator of whether they were allopathically trained or osteopathically trained, and 3) an indicator of whether they were a US Medical Graduate (USMG) or International Medical Graduate (IMG). This information was merged with ABFM administrative data indicating whether they ever sat for the ABFM certification examination before December 2016.

\section{Participants}

The participants were residents who graduated from ACGME-accredited family medicine residency programs between 2006 and 2016. All residents were classified by their educational background as USMG-MD, USMG-DO, or IMG-MD.

The data used in this study was deemed exempt by the American Academy of Family Physicians Institutional Review Board. Furthermore, the procedures were reviewed by ABFM senior executive staff to ensure that $\mathrm{ABFM}$ privacy policies were not violated.

\section{Analyses}

After classifying the residents, we cross-tabulated the data by graduation year and by educational background (USMG-MD, USMG-DO, or IMG-MD) to examine the cohort composition trend over time. We further calculated the number of residents who sat for the ABFM certification examination to determine the proportion of USMGs, IMGs, allopaths, and osteopaths that elect to certify with the ABFM.

\section{Results}

Table 1 shows a comparison between the number and proportion of osteopathic physicians and allopathic physicians by year of completion of training in family medicine. Not only does the number of osteopaths continue to rise, but they are also constituting a greater percentage of those completing residency training. Furthermore, in recent years a decline in both the total number and proportion of IMG-MDs graduating from family medicine resi- 
Figure 1. Proportion of graduating residents (2006-2016) by medical training and degree type. USMG-MD, US Medical Graduate-MD; USMG-DO, US Medical Graduate-DO; IMG-MD, International Medical Graduate-MD.

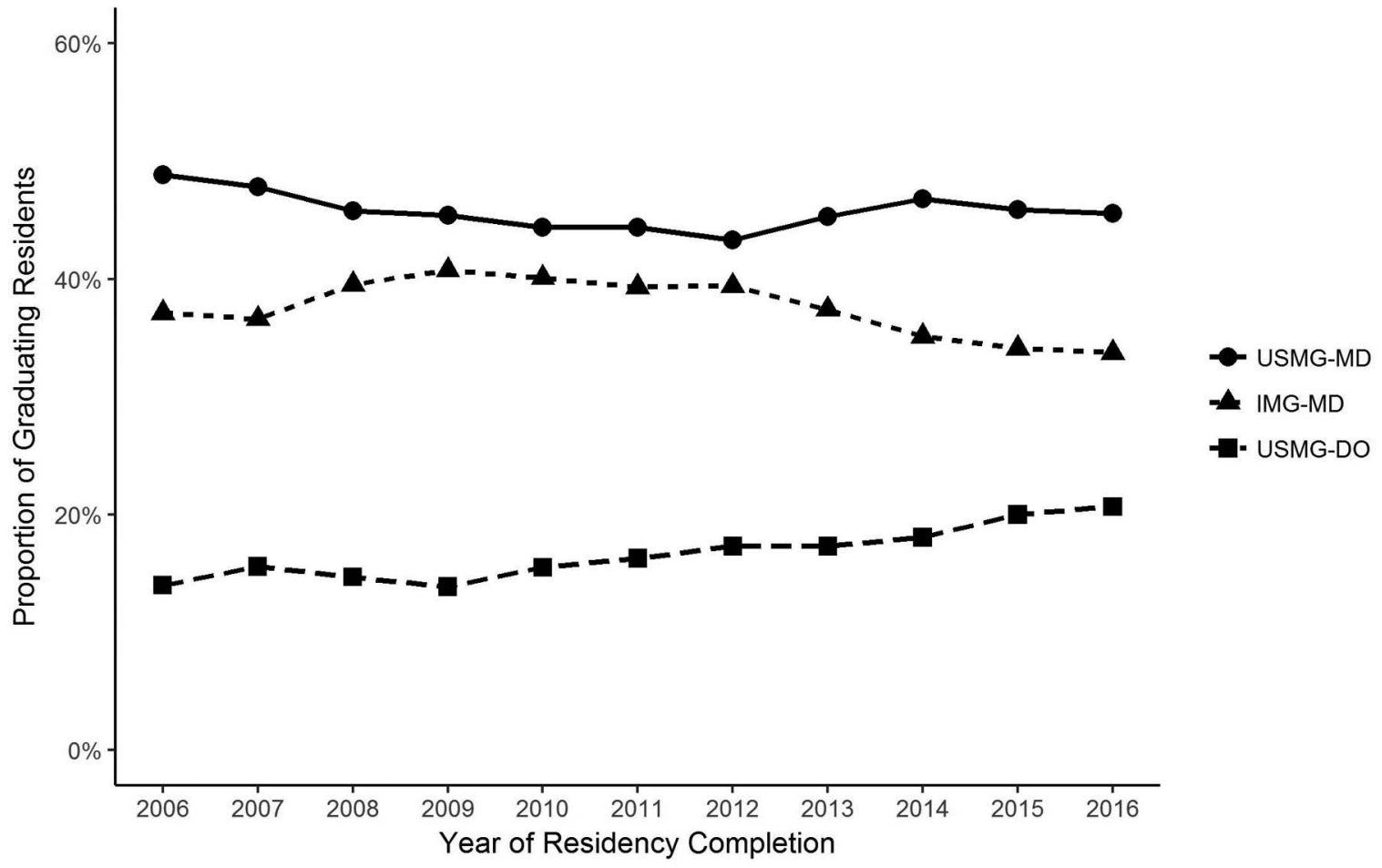

dency programs is observed. Although the number of USMG-MDs has been rising, it has been doing so at a similar rate to the increase in the total number of graduating residents, leading to relatively stable proportions. Figure 1 more clearly illustrates the rise in USMG-DOs relative to the decline in IMG-MDs.
Table 2 shows the number of residents who completed an ACGME-accredited family medicine residency program by completion year. This table also shows the number of those graduates from each year who elected to take the ABFM's certification examination at any time since completion of their training (henceforth referred to as Takers)

Table 2. Residents Who Take the ABFM Exam by Year of Residency Completion

\begin{tabular}{|c|c|c|c|c|c|c|c|c|c|}
\hline \multirow{2}{*}{$\begin{array}{l}\text { Year of Residency } \\
\text { Completion }\end{array}$} & \multicolumn{3}{|c|}{ USMG-DO } & \multicolumn{3}{|c|}{ IMG-MD } & \multicolumn{3}{|c|}{ USMG-MD } \\
\hline & Total (N) & Takers & Take Rate (\%) & Total $(\mathrm{N})$ & Takers & Take Rate & Total (N) & Takers & Take Rate (\%) \\
\hline 2006 & 444 & 396 & 89.2 & 1177 & 1154 & 98.0 & 1549 & 1526 & 98.5 \\
\hline 2007 & 491 & 430 & 87.6 & 1153 & 1122 & 97.3 & 1505 & 1490 & 99.0 \\
\hline 2008 & 459 & 372 & 81.0 & 1234 & 1211 & 98.1 & 1428 & 1409 & 98.7 \\
\hline 2009 & 441 & 351 & 79.6 & 1296 & 1265 & 97.6 & 1443 & 1429 & 99.0 \\
\hline 2010 & 485 & 388 & 80.0 & 1253 & 1231 & 98.2 & 1386 & 1367 & 98.6 \\
\hline 2011 & 525 & 400 & 76.2 & 1268 & 1233 & 97.2 & 1431 & 1418 & 99.1 \\
\hline 2012 & 563 & 434 & 77.1 & 1282 & 1264 & 98.6 & 1408 & 1395 & 99.1 \\
\hline 2013 & 557 & 483 & 86.7 & 1204 & 1185 & 98.4 & 1457 & 1449 & 99.5 \\
\hline 2014 & 612 & 540 & 88.2 & 1190 & 1165 & 97.9 & 1586 & 1571 & 99.1 \\
\hline 2015 & 681 & 647 & 95.0 & 1162 & 1142 & 98.3 & 1564 & 1548 & 99.0 \\
\hline 2016 & 718 & 680 & 94.7 & 1172 & 1137 & 97.0 & 1583 & 1549 & 97.9 \\
\hline Total & 5976 & 5121 & 85.7 & 13,391 & 13,109 & 97.9 & 16,340 & 16,151 & 98.8 \\
\hline
\end{tabular}

USMG-DO, US Medical Graduate-DO; USMG-MD, US Medical Graduate-MD; IMG-MD, International Medical Graduate-MD. 
Figure 2. ABFM Certification Examination Take Rate (2006-2016) by medical training and degree type. USMG-MD, US Medical Graduate-MD; USMG-DO, US Medical Graduate-DO; IMG-MD, International Medical Graduate-MD.

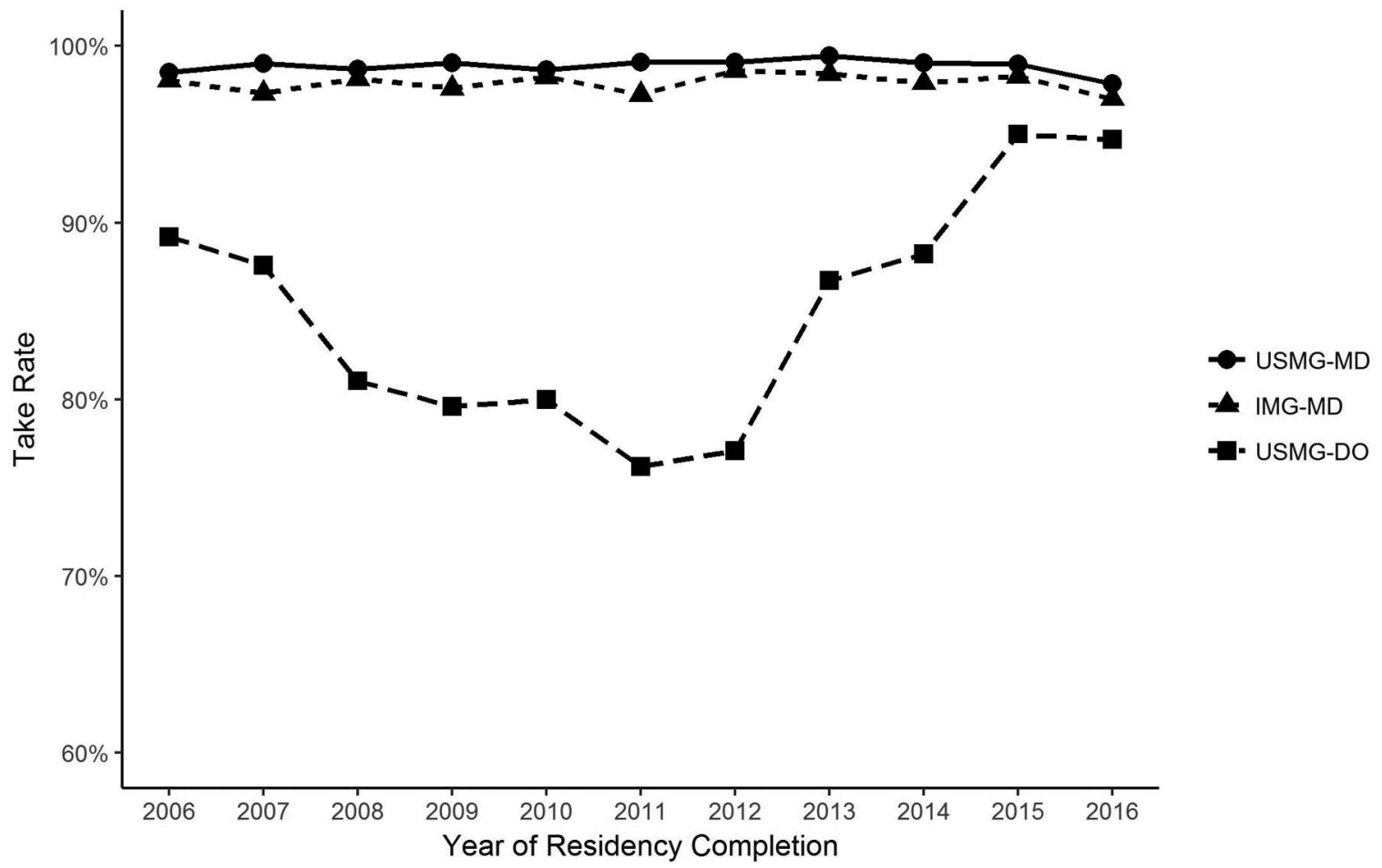

and the associated percentage of those graduates (Take Rate). The Take Rate for USMG-MDs and USMG-IMGs seems relatively stable; however, the Take Rate for the USMG-DOs dropped between 2006 and 2011, but since 2012 the Take Rate continued to climb to its high point in 2015 when $95.0 \%$ of the graduates elected to sit for the ABFM certification examination. Figure 2 is provided to illustrate this rise in the percentage of USMG-DOs taking the ABFM's certification examination.

\section{Discussion}

Our findings suggest that the increasing numbers of physicians educated in osteopathic medical schools entering training in ACGME-accredited family medicine residency training programs has had a substantial impact on the composition of trainees preparing for careers in family medicine as well as electing for certification by the ABFM. As noted in Table 1 and Figure 1, both the number and proportion of IMGMDs are decreasing while the number and proportion of USMG-DOs are increasing. The increase in the number of DOs should not be surprising as the number of first-year enrollees in osteopathic medical schools has more than doubled since 2001. ${ }^{2}$ Further- more, in 2013 the National Residency Matching Program (NRMP) instituted their "All-In" policy, which that stipulates residencies participating in the Match cannot sign applicants outside of the $\mathrm{Match}^{3}$, potentially eliminating the ability of IMGs to sign outside of the match and increasing their direct competition with USMG-DOs for Match spots. ${ }^{4}$

The work of Biggs et $\mathrm{al}^{4}$ and Kozakowski et $\mathrm{al}^{5}$ provides a framework for understanding trends in the volume and training of medical graduates entering family medicine residency. Their analyses of the NRMP are strikingly similar to our findings, confirming the increase in osteopaths entering family medicine training. Like our data, however, these analyses were limited in that they considered only ACGME-accredited programs.

Interestingly, Kozakowski et $\mathrm{al}^{5}$ note that the number of US citizen IMGs entering residency is increasing while the number of non-US citizen IMGs is declining.

When osteopathic physicians graduate from an ACGME-accredited or dually-accredited ACGME/ AOA residency program, they are eligible to certify with 1 of the 24 member boards of the American Board of Medical Specialties (ABMS), 1 of the 18 
specialty boards of the AOA, or both. Recent estimates indicate that $75 \%$ of licensed physicians in the United States hold a certification from an ABMS board ${ }^{5}$, whereas only $38 \%$ of osteopathic physicians held an ABMS board certification. Similarly, only $40 \%$ of licensed osteopathic physicians were found to have a certification by an AOA board. ${ }^{6}$ Given that ABMS and AOA boards typically do not share information about their diplomates with each other, the number of osteopathic physicians who hold certifications from both ABMS and AOA member boards is not known. One survey of osteopathic program directors of dually accredited family medicine residency programs reported $66 \%$ of program directors indicated that less than half of their program's osteopathic graduates elected to certify with both the ABFM and the American Osteopathic Board of Family Practice. ${ }^{7}$ Another study ${ }^{8}$ found that approximately $86 \%$ of residents in dually accredited programs were opting for ABFM certification.

Significant changes in ACGME family medicine program requirements most likely affected the rate at which osteopathic residents elected to take the ABFM certification examination. In 2013, the ACGME approved new program requirements for family medicine residency training that went into effect on July 1 , 2014 , requiring that $95 \%$ of a program's graduates would have taken the ABFM certification on a 5 -year rolling average (V.C.4) in addition to the requirement that $90 \%$ of the graduates pass the ABFM examination (V.C.5). ${ }^{9}$ In an effort to assist program directors with meeting the ACGME's new Take-Rate requirement ${ }^{9}$, in 2012 the ABFM changed the timing of the certification examination from July to April. ${ }^{10}$ Moving the examination date before completion of residency allowed program directors to encourage the examination-taking behavior of their residents to meet the new Take-Rate requirement. This likely had a direct impact on the increased Take Rate noted for osteopathic residents who had trained in dually accredited programs.

\section{Limitations}

Although the ABFM does know the number of osteopathic residents training in ACGME-accredited family medicine residency programs, it is still not known whether an osteopathic physician who does not certify with the ABFM has opted for alternate certification or simply decided not to certify. This piece of information will be essential to better understand the characteristics of the boardcertified family physician workforce.

\section{Summary}

Our data clearly demonstrate the changing composition of graduating trainees entering the family medicine workforce. As the transition to a single accreditation system for graduate medical education progresses over the next 4 years, further shifts in the composition of this workforce should be expected. Collaborations with the American Osteopathic Board of Family Physicians could further help to understand the certification dynamics of all trainees completing formal family medicine training and entering the primary care workforce.

To see this article online, please go to: http://jabfm.org/content/ 30/6/838.full.

\section{References}

1. MDs and DOs moving toward a single, unified accreditation system for graduate medical education. [News Release]. October 24, 2012. Available from: http://www.acgme.org/Portals/0/PDFs/10-24-2012 PressRelease.pdf.

2. Trends in osteopathic medical school applicants, enrollment and graduates. Chevy Chase, MD: American Association of Colleges of Osteopathic Medicine; 2014.

3. The National Residency Match Program. Available from: http://www.nrmp.org/policies/all-in-policy/ all-in-policy-main-residency-match/.

4. Biggs WS, Crosley PW, Kozakowski SM. Results of the 2013 National Resident Matching Program: Family Medicine. Fam Med 2013;45:647-651.

5. Kozakowski SM, Crosley PW, Bentley A. Results of the 2014 National Resident Matching Program: Family Medicine. Fam Med 2014;46:701-706.

6. Ayres RE, Scheinthal S, Gross S, Bell EC. Osteopathic Specialty Board Certification. J Am Osteopath Assoc 2009; 109:181-190.

7. Terry R, Hill F. Analysis of AOA/ACGME Accredited Family Medicine Residency Program. Fam Med 2011; 43:387-391.

8. O’Neill TR, Royal KD, Schulte BM, Leigh T. Comparing the Performance of Allopathically and Osteopathically Trained Physicians on the American Board of Family Medicine's Certification Examination. July 2009. ERIC ED506669. Available from: http://files.eric.ed.gov/fulltext/ED506669.pdf.

9. ACGME Program Requirements for Graduate Medical Education in Family Medicine. Available from: http://www.acgme.org/portals/0/pfassets/ programrequirements/120_family_medicine_2016.pdf.

10. The ABFM MC-FP exam moves to April beginning in 2012. [Newsletter]. The Phoenix. Lexington, KY; 2012. 